\title{
Zero-fluoroscopy ablation in patients with cardiac electronic implantable devices
}

\author{
Keiko Shimamoto $^{1}$, Kennichiro Yamagata ${ }^{1}$, Akinori Wakamiya ${ }^{1}$, Nobuhiko Ueda ${ }^{1}$, Tsukasa \\ Kamakura $^{1}$, Mitsuru Wada ${ }^{1}$, Yuko Inoue ${ }^{1}$, Koji Miyamoto ${ }^{1}$, Satoshi Nagase ${ }^{1}$, and Kengo \\ Kusano $^{1}$ \\ ${ }^{1}$ National Cerebral and Cardiovascular Center
}

September 24, 2021

\begin{abstract}
Introduction: Utilizing a 3-dimensional (3-D) mapping system and intracardiac echocardiography (ICE) has allowed ablation procedures with less or without fluoroscopy; however, there is limited data for patients with cardiac electronic implantable device (CIED) leads regarding the suspected risk of lead injury. Therefore, we sought to explore technics to perform safe trans-septal approach and catheter manipulation technique in patients with CIED leads. Methods and Results: This study comprised 68 consecutive patients (45 [66.2\%] males, median [interquartile range] 73 [68-77] years old) with CIED who underwent catheter ablation for supraventricular tachycardia, 16 without fluoroscopy (zero-fluoro group) and 52 with fluoroscopy (conventionalfluoro group), between July 2019 and April 2021. All procedures were performed under a 3-D mapping system and ICE guidance. We compared the differences in treatment and development of complications between the two groups. The procedures were mainly atrial fibrillation $(73.6 \%)$ and atrial tachycardia. The median time from venipuncture to trans-septal procedure (zerofluoro vs. conventional-fluoro group: $27.0 \mathrm{~min}$ vs. $23.5 \mathrm{~min}, \mathrm{P}=0.71)$ and total procedure time (215 min vs. $172 \mathrm{~min}, \mathrm{P}=0.55)$ were not different between the two groups. The acute procedural success rate $(100 \%$ vs. $98.1 \%, \mathrm{P}=1.00)$ and reduction of atrial high-rate episodes at 6 months $(3.2[0.3-93.9] \%$ vs. $1.0[0.0-14.9] \%, \mathrm{P}=0.33)$ did not differ between the two groups. No patient showed lead-related complications in both groups. Conclusions: Zero-fluoro ablation for supraventricular arrhythmia using 3-D mapping and ICE in patients with CIED leads was feasible under careful catheter manipulation.
\end{abstract}

\section{Zero-fluoroscopy ablation in patients with cardiac electronic implantable devices}

Keiko Shimamoto, MD ${ }^{\text {a.b }}$; Kenichiro Yamagata, MD, $\mathrm{PhD}^{\mathrm{a}}$; Akinori Wakamiya, $\mathrm{MD}^{\mathrm{a}}$; Nobuhiko Ueda, MD, $\mathrm{PhD}^{\mathrm{a}}$; Tsukasa Kamakura, MD, $\mathrm{PhD}^{\mathrm{a}}$; Mitsuru Wada, $\mathrm{MD}^{\mathrm{a}}$; Yuko Inoue, MD, $\mathrm{PhD}^{\mathrm{a}}$; Koji Miyamoto, $\mathrm{MD}$, $\mathrm{PhD}^{\mathrm{a}}$; Satoshi Nagase, MD, $\mathrm{PhD}^{\mathrm{a}}$; Kengo F. Kusano MD, $\mathrm{PhD}^{\mathrm{a}}$

${ }^{a}$ Department of Cardiovascular Medicine, National Cerebral and Cardiovascular Center

${ }^{\mathrm{b}}$ Department of Molecular Imaging in Cardiovascular Medicine, Graduate School of Medicine, Osaka University, Suita

Address for authors:

Department of Cardiovascular Medicine, National Cerebral and Cardiovascular Center,

6-1 Kishibe-Shimmachi, Suita, Osaka 564-8565, Japan

\section{Corresponding Author:}

Dr. Kenichiro Yamagata 
Department of Cardiovascular Medicine, National Cerebral and Cardiovascular Center,

6-1 Kishibe-Shimmachi, Suita, Osaka 564-8565, Japan

Tel: +81-6-6170-1070; Fax: +81-6-6833-9865

Email: look.tky@ncvc.go.jp

\title{
Funding
}

This research was supported by a research grant from Medtronic Japan (\#1009, Kengo Kusano)

\section{Data Availability}

The dataset from this study is held securely by the National Cerebral and Cardiovascular Center and is available from the corresponding author on reasonable request.

\section{Informed consent}

Written informed consent was obtained from all subjects before undergoing the ablation procedure.

\section{Ethical approval}

The National Cerebral and Cardiovascular Center Institutional Review Board approved this study (M26148-12).

\section{Reprint requests}

None

\section{Conflict of interests}

The authors have no conflicts of interest to disclose.

\begin{abstract}
Introduction: Utilizing a 3-dimensional (3-D) mapping system and intracardiac echocardiography (ICE) has allowed ablation procedures with less or without fluoroscopy; however, there is limited data for patients with cardiac electronic implantable device (CIED) leads regarding the suspected risk of lead injury. Therefore, we sought to explore technics to perform safe trans-septal approach and catheter manipulation technique in patients with CIED leads.

Methods and Results: This study comprised 68 consecutive patients (45 [66.2\%] males, median [interquartile range] 73 [68-77] years old) with CIED who underwent catheter ablation for supraventricular tachycardia, 16 without fluoroscopy (zero-fluoro group) and 52 with fluoroscopy (conventional-fluoro group), between July 2019 and April 2021. All procedures were performed under a 3-D mapping system and ICE
\end{abstract}


guidance. We compared the differences in treatment and development of complications between the two groups. The procedures were mainly atrial fibrillation $(73.6 \%)$ and atrial tachycardia. The median time from venipuncture to trans-septal procedure (zero-fluoro vs. conventional-fluoro group: 27.0 min vs. 23.5 $\min , \mathrm{P}=0.71)$ and total procedure time $(215 \mathrm{~min}$ vs. $172 \mathrm{~min}, \mathrm{P}=0.55)$ were not different between the two groups. The acute procedural success rate $(100 \%$ vs. $98.1 \%, \mathrm{P}=1.00)$ and reduction of atrial high-rate episodes at 6 months $(3.2[0.3-93.9] \%$ vs. $1.0[0.0-14.9] \%, \mathrm{P}=0.33)$ did not differ between the two groups. No patient showed lead-related complications in both groups.

\section{Conclusions:}

Zero-fluoro ablation for supraventricular arrhythmia using 3-D mapping and ICE in patients with CIED leads was feasible under careful catheter manipulation.

\section{Keywords}

catheter ablation, artificial pacemakers, implantable defibrillators, echocardiography, intracardiac imaging technique

\section{INTRODUCTION}

Cardiac ablation is a well-established therapy for supraventricular tachycardia ${ }^{1}$. Fluoroscopy has been used as a major imaging tool during the procedure. However, accumulating ionizing radiation exposure and orthopedic problems caused by radiological personal protective equipment have been focused on in recent years $^{2,3}$. Therefore, strategies to minimize fluoroscopy during the procedure have been explored to achieve the As Low As Reasonably Achievable (ALARA) principle these days. In recent years, development in 3dimensional (3-D) electroanatomical mapping systems and the use of intracardiac echocardiography (ICE) have made it possible to perform procedures safely with less radiation exposure ${ }^{4}$.

Meanwhile, the number of patients requiring cardiac electronic implantable devices (CIEDs) is consistently increasing with time due to global aging ${ }^{6}$. However, an evaluation of the reduction of fluoroscopy procedures in patients with CIED leads has been limited due to possible lead troubles during catheter manipulation. Therefore, we explored technics to perform safe trans-septal approach and catheter manipulation in patients with CIED leads using the zero-fluoroscopy technique. We also compared applied procedures and complications in these patients with those who underwent the catheter ablation using fluoroscopy.

\section{METHODS}

\section{Patients}

This study comprised 68 consecutive patients with transvenous cardiac implantable electronic devices who underwent catheter ablation for supraventricular tachycardia between July 2019 and April 2021. We excluded one patient who was diagnosed with congenitally corrected transposition of the great arteries and dextrocardia for different anatomical structures. Finally, this study comprised 16 patients who underwent catheter ablation without fluoroscopy (zero-fluoro group) and 52 patients who underwent conventional ablation procedures using fluoroscopy (conventional-fluoro group). We obtained clinical background data of the patients from their medical charts. All participants provided written informed consent before undergoing the ablation procedure, and the Institutional Review Board of the National Cerebral and Cardiovascular Center approved this retrospective analysis of the patients' clinically acquired data (M26-148-12). 


\section{Ablation procedures:}

All patients were sedated with propofol and dexmedetomidine. The electrophysiological study was performed using the 3-D mapping system (CARTOß3: Biosense Webster, Diamond Bar, CA, EnSite Precision; Software version 2.0.1 Abbott, Chicago, IL, or RHYTHMIA HDx, Boston Scientific, Marlborough, MA) combined with ICE guidance (ACUSON AcuNav; Biosense Webster, SOUNDSTAR(r); Biosense Webster, or ViewFlex Xtra; St. Jude Medical, St. Paul, MN). All patients received 5,000 U of unfractionated heparin at first and continuous infusion to attain targeted activated clotting time of 300-400 s until the end of the left atrial procedure.

\section{Catheter placement and trans-septal puncture:}

In the zero-fluoro group, we used the CARTO3 system. We performed venipuncture of the jugular and femoral veins under ultrasound guidance ${ }^{6}$. Long spring wires were used in the femoral vein approach to prevent wires from straying into small vessels. First, we inserted ICE from the left femoral vein and proceeded to the right atrium (RA). After confirming the position of the leads and the other wires were in the RA, two long sheaths (Agilis NxT Steerable Introducer; Abbott, or CARTO VIZIGO Bi-Directional Guiding Sheath; Biosence Webstar, and Swartz SL0 sheath; St. Jude Medical) were inserted. Each lead's position in the RA was acquired by SOUNDSTAR(r), which is ICE incorporating a navigation sensor, and projected to the 3-D mapping (Figure 1A). Then we positioned the catheter in the coronary sinus (CS). We used a 10-electrode catheter (DecaNAV Catheter; Biosense Webster) for insertion via the inferior vena cava (IVC) and a 20-electrode atrial cardioversion catheter (BeeAT; Japan Lifeline Co., Tokyo, Japan) for insertion via the superior vena cava (SVC). As creating a hybrid model by the manufacturer-specific catheter helps visualization of non-sensor catheters on the CARTO3 system, we acquired the magnetic matrix fields of the RA and CS using the ablation catheter in advance before BeeAT insertion. A fast anatomical map (FAM) of the CS was also obtained for anatomical guidance. Subsequently, we inserted a catheter into the RA under the 3-D mapping guidance, proceeded close to the tip of the ICE, which was placed at the height of the CS ostium, put the catheter at the CS entrance, and directly inserted it into the CS confirming both atrial and ventricular potentials were obtained on the electrode ${ }^{7}$. We also visually confirmed using ICE that the catheter was not entangled with the lead.

To achieve trans-septal access, we directly positioned the tip of the long sheath next to the atrial septum, confirmed the sheath was not being entangled to the leads, inserted the trans-septal needle (NRG RF Transseptal Needle; Baylis Medical Company Inc, Montreal, Canada) into the sheath, punctured toward the left pulmonary vein $(\mathrm{PV})$, and needle and sheath penetration to the LA were confirmed by saline injection by ICE (Figure 1B: Direct approach). The wire was inserted to the left superior PV and the septum was dilated with the sheath. After retracting the sheath, we advanced the ablation catheter into the second sheath to the LA and achieved two sheath insertions through a single puncture hole.

In the conventional-fluoro group, wire and sheath positionings and catheter manipulation were performed under a combination of 3-D mapping, ICE, and fluoroscopic guidance. The long sheath was placed at the SVC through the long wire before the trans-septal procedure, the needle was inserted into the sheath, dragging down caudally until the tip of the sheath flip and fell into the fossa under anteroposterior fluoroscopic projection (Figure 1B: Conventional approach). Needle direction and the puncture site were confirmed with both fluoroscopy and ICE. The leads positions and interaction with wires and catheters were checked carefully with fluoroscopy and ICE.

\section{Mapping and ablation:}

Leads were carefully observed using ICE, especially during mapping or ablating the RA. We limited the catheter movement to a 180deg turn when we manipulated the catheter above the deflection of the CIED leads. To avoid trapping the lead and dislodging it, we ensured that the catheter was not entangled in the leads when pulling it downward (Figure 1C). 
PV isolation was achieved, and the bi-directional block was confirmed in all patients with atrial fibrillation (AF). Cavotricuspid isthmus ablation was performed for patients who showed typical atrial flutter. Other ablation strategies were left to each operator.

The anatomical and voltage maps were obtained using a multipolar mapping catheter (PentaRay(r) NAV eco Catheter; Biosense Webster, Advisor HD Grid Mapping Catheter, Sensor Enabled; Abbott, Orion(r); Boston Scientific). We used FAM as the main anatomical guidance for PV isolation and other linear ablation in the zero-fluoro group. ICE was used to perform ablation out of the PVs to avoid stenosis. Preprocedural computed tomography imaging was not mandatory for the procedure.

[insert Figure 1]

\section{Pacemaker check and follow-up of arrhythmia:}

Pacing mode was set to trigger or asynchronous mode, and the shock device was deactivated during the procedure. Pacemaker lead testing was performed before discharging every patient. A lead complication was defined as apparent lead dislodgment or pacing/sensing threshold change requiring pacemaker setting change. Acute procedural success was defined as the establishment of a bi-directional electrical conduction block in all linear ablations and the termination of all identified sustained atrial tachycardia. Clinical success was assessed after a 3-month blanking period. Atrial high-rate episodes lasting more than 1 min detected by devices were considered as recurrence. Recurrence rate was assessed in the patients who underwent device check at least 6 months after the procedure. In these patients, 3 months AF burden from after blanking period to 6 months was compared to preoperative values.

\section{Measurements:}

Time from the puncture to the sheath out was measured in all cases. Time from the puncture to achieve trans-septal approach was measured in the patients who underwent trans-septal procedures just after CS catheter placement. Total fluoroscopy time and doses were counted in the conventional-fluoroscopy group. For the fluoroscopy, the pulse setting was reduced to 2 pulse/s and the EP mode setting was used provided by the fluoroscopy vendor to reduce radiation exposure.

\section{Statistical analysis}

Quantitative variables were expressed as the median (interquartile range); the Mann-Whitney U test was employed to compare continuous variables. Categorical variables were presented as number (n) and percentage (\%) and compared with the chi-square test or Fisher's exact test. Statistical analyses were performed using EZR (Saitama Medical Center, Jichi Medical University, Saitama, Japan; Ver 1.51) ${ }^{8}$, which is a graphical user interface for R (The R Foundation for Statistical Computing, Vienna, Austria).

\section{RESULTS}

\section{Baseline characteristics:}

Patients' baseline characteristics and implanted device information are summarized in Table 1. Of the 68 patients, $45(66.2 \%)$ were males, and the median age was $73(68-77)$ years. The majority of the patients $50(73.6 \%)$ underwent ablation for AF, the median duration of arrhythmia was 55 (15-201) months, and 19 (27.9\%) received previous AF ablation. These results were not significantly different between the zero-fluoro and conventional-fluoro groups. Conversely, the zero-fluoro group comprised less paroxysmal AF (zero-fluoro versus [vs.] conventional-fluoro group: $18.8 \%$ vs. $61.5 \%$ ) and more persistent AF (14.8\% vs. 15.4\%), and atrial tachycardia ( $50.0 \%$ vs. $19.2 \%$ ). Every patient had transvenous pacing device implantation. One patient 
in the conventional-fluoro group used a single VDD lead, while the others used the atrial and ventricular leads, including one patient who had the implantation of the atrial and ventricular leads through persistent left SVC. Lead tip positions in the atrium and ventricle were not different between the two groups, while patients in the conventional-fluoro group were more likely to have shock devices and LV leads. The median time from lead implantation was 54.5 months, and 5 (7.4\%) patients in the conventional-fluoro group received new lead implantation within 3 months before the ablation procedure.

[insert Table 1]

\section{Ablation procedure:}

Table 2 shows the detailed ablation procedure. PV isolation using the cryoablation balloon was performed in the conventional-fluoro group, and one patient received additional RF application to achieve PV electrical isolation. CS catheter was inserted in $63(92.6 \%)$ of the patients, and the insertion procedure was more likely to be approached via IVC in the zero-fluoro group than the conventional-fluoro group $(33.3 \% \mathrm{vs} .4 .2 \%, \mathrm{P}=$ 0.007).

The trans-septal procedure was successfully done for all patients in the zero-fluoro group and 48 (92.3\%) in the conventional-fluoro group. The median time from venipuncture to the trans-septal procedure was measured in $15(93.8 \%)$ patients and $42(80.8 \%)$ patients and it was not significantly different between the two groups (27.0 [17.5-34.0] $\min$ vs. $23.5[20.0-27.8] \mathrm{min}, \mathrm{P}=0.71)$.

PV isolation was performed in $80.9 \%$ of the patients. As shown in Table 2, more patients in the zero-fluoro group received left atrial linear ablation and focal ablation procedures from the RA compared to those in the conventional-fluoro group. When limited to the radiofrequency ablation, the total radiofrequency application time was not different. (1715 [1189-2401] s vs. 1552 [1235-2187] s, $\mathrm{P}=0.92)$. The total procedure time was not significantly different in the zero-fluoro and conventional-fluoro groups (215 [138-268] min, vs. 172 [156-214) $\min , \mathrm{P}=0.55)$.

\section{Success and recurrence rates:}

Acute procedural success was achieved in $100 \%$ of cases in the zoro-fluoro group and $98.1 \%$ in the conventional-fluoro group, respectively, and did not differ between the two groups $(\mathrm{P}=1.00)$. Followup at 6 months after ablation was obtained in $58(85.3 \%)$ patients and the recurrence rate in the zero-fluoro and conventional-fluoro was not different (53.8\% vs. $33.3 \%, \mathrm{P}=0.20)$. Median AF burden at 6 months after the procedure decreased from $10.4 \%$ to $0.0 \%$. There was no difference in the amount of burden reduction between the two groups $(3.2[0.3$ to 93.9$] \%$ vs. $1.0[0.0$ to 14.9$] \%, \mathrm{P}=0.33)$.

\section{Complications:}

No patient showed lead-related complications in each group, predefined apparent lead dislodgment nor pacing/sensing threshold change within 3 months of follow-up. Over the study period, one patient in the conventional-fluoro group developed asymptomatic hemidiaphragmatic paresis after SVC isolation, which had resolved a month later. No other serious complications related to the procedure, including cardiac tamponade, bleeding which required a transfusion, puncture site trouble, thromboembolism, stroke, symptomatic phrenic nerve palsy, or left atrial to esophageal fistula were observed.

None of the patients who were planned for zero-fluoro ablation required fluoroscopy for any reason during the procedure.

[insert Table 2] 


\section{DISCUSSION}

To the best of our knowledge, this is the first study to focus on the zero-fluoro ablation procedure results in patients with CIED leads. The main findings were as follows: 1) 16 patients completed ablation for supraventricular arrhythmia without fluoroscopy and no serious complication including lead injury was observed; 2) time to achieve trans-septal puncture or total procedure time was not different regardless of fluoroscopic use; and 3) the acute procedural success rate, recurrence rate, and reduction of atrial high-rate episodes at 6 months did not differ.

The development of a 3-D mapping system has allowed us to undergo ablation procedures with less radiation exposure $^{9}$. Although more evidence to show safety in reduced or zero-fluoro ablation for supraventricular arrhythmia has been shown ${ }^{10-12}$; thus far, there is limited data for patients with CIED leads. The primary concern in these cases is the risk of direct lead injury during radiofrequency application and lead dislodgment during catheter manipulation. A previous prospective study on the effect of the radiofrequency application on pacemaker leads showed the importance of keeping a certain distance from the lead tips using fluoroscopic imaging to avoid interference ${ }^{13}$. Therefore, we utilized SOUNDSTAR(r) in all cases in the zero-fluoro group to project the CIED leads to the 3-D mapping for rough location reference and monitor the real-time lead position during catheter manipulation.

Generally, as a reduced or zero-fluoro procedure requires a certain training period to perform ${ }^{9}$, this procedure should be performed under the guidance of an established operator at the beginning. Assessment of the lead positionings and pacemaker dependency should also be warranted. We should select suitable patients to balance the merit of reduction against the risk of undergoing zero-or reduced fluoro ablation. Meanwhile, more patients, including pregnant women or those who have heart failure, are recommended or eligible for cardiac ablation for supraventricular arrhythmia than ever before ${ }^{14,15}$. The former requires more attention to reduce fluoroscopy dose to avoid fetal radiation exposure, and the latter involves some number of CIED implanted patients. In addition, the CASTLE-AF trial, which reported a significant reduction of a composite of death from any cause or hospitalization for worsening heart failure in ablation therapy for AF compared to the medical therapy arm, was for patients with heart failure with CIED implantation. In fact, more than $30 \%$ of the patients in this study had a history of heart failure, and $17.6 \%$ had cardiac resynchronization therapy (CRT) implantation. Therefore, since the number of ablations for patients with the implanted device is expected to increase in the future, learning these methods would be helpful in any case.

It has been reported that an ICE-guided trans-septal puncture can be performed safely without fluoroscopy, but caution should be exercised in applying these results to patients with CIED due to possible lead dislocation risk ${ }^{16}$. In this study, we explored different techniques to avoid lead injury. To achieve trans-septal puncture, we approached directly to the atrial septum instead of dragging it down from the SVC to avoid entangling with leads in the zero-fluoro procedure. This approach was also previously proven safe in the trans-septal approach without fluoroscopy ${ }^{17}$. Our results, which showed a great success rate without complication or prolonged procedure time, support the use of this approach for these patients with pacemaker leads.

In addition, total procedure time was not prolonged without using fluoroscopy assistance. There were fewer paroxysmal and more persistent $\mathrm{AF}$ and patients with atrial tachycardia leading to additional LA linear ablation in the zero-fluoro group, which could have resulted in longer procedure time ${ }^{18}$; however, total procedure time was not different regardless of fluoroscopy use. Therefore, a longer procedure time is not considered as a practical reason to avoid this procedure.

To date, approximately half of the guideline writing group reported having used ICE during the ablation procedure for assuring safety ${ }^{19}$. We used both a 3-D mapping system and ICE to ensure safety in all the patients who required a trans-septal approach, including the conventional-fluoroscopy group. However, physicians not using ICE routinely should weigh the benefits and disadvantages including the cost of ICE. An alternative reported system to reduce fluoroscopy during ablation is the integration of prerecorded Xray imaging using the MediGuide system $(\text { Abbott })^{6}$ or CARTO-UNIVU Module of CARTO(r) 3 system 
$(\text { Biosense Webster })^{20}$, and these systems could also provide a still image of the leads position. Nevertheless, as we have to monitor unfixed lead position timely throughout the procedure, live imaging acquired by either ICE or fluoroscopy is required for completing the procedure safely.

\section{LIMITATIONS}

The results of our study were limited by the single-center, retrospective design of the study and the relatively small sample size. As the patients included in this study had complexed underlying heart conditions, reflected by $17.6 \%$ implantation rate of CRT-D and various type of arrhythmias, long term efficacy of the procedure require further investigation.

\section{CONCLUSIONS}

Zero-fluoro ablation for supraventricular arrhythmia using 3-D mapping and ICE in patients with transvenous pacing leads was feasible under careful catheter manipulation.

\section{Acknowledgments}

We would like to thank Editage (www.editage.com) for English language editing.

\section{Reference list}

1. Brugada J, Katritsis DG, Arbelo E, Arribas F, Bax JJ, Blomstrom-Lundqvist C, et al. 2019 ESC Guidelines for the management of patients with supraventricular tachycardiaThe Task Force for the management of patients with supraventricular tachycardia of the European Society of Cardiology (ESC): Developed in collaboration with the Association for European Paediatric and Congenital Cardiology (AEPC). Eur Heart J 2020; 41: 655-720.

2. Fazel R, Krumholz HM, Wang Y, Ross JS, Chen J, Ting HH, et al. Exposure to Low-Dose Ionizing Radiation from Medical Imaging Procedures. N Engl J Med 2009; 361: 849-857.

3. Orme NM, Rihal CS, Gulati R, Holmes DR, Jr., Lennon RJ, Lewis BR, et al. Occupational health hazards of working in the interventional laboratory: a multisite case control study of physicians and allied staff. J Am Coll Cardiol 2015; 65: 820-826.

4. Sommer P, Bertagnolli L, Kircher S, Arya A, Bollmann A, Richter S, et al. Safety profile of near-zero fluoroscopy atrial fibrillation ablation with non-fluoroscopic catheter visualization: experience from 1000 consecutive procedures. Europace 2018; 20: 1952-1958.

5. Zecchin M, Torre M, Carrani E, Sampaolo L, Ciminello E, Ortis B, et al. Seventeen-year trend (2001-2017) in pacemaker and implantable cardioverter-defibrillator utilization based on hospital discharge database data: An analysis by age groups. Eur J Intern Med 2021; 84: 38-45.

6. Yamagata K, Wichterle D, Roubicek T, Jarkovsky P, Sato Y, Kogure T, et al. Ultrasound-guided versus conventional femoral venipuncture for catheter ablation of atrial fibrillation: a multicentre randomized efficacy and safety trial (ULTRA-FAST trial). Europace 2018; 20: 1107-1114.

7. Shimamoto K, Yamagata K, Kamiya C, Kusano KF. Zero-fluoro atrial flutter ablation in a pregnant woman with a pacemaker. BMJ Case Reports 2021; 14: e240671. 
8. Kanda Y. Investigation of the freely available easy-to-use software 'EZR' for medical statistics. Bone Marrow Transplant 2013; 48: 452-458.

9. Pani A, Giuseppina B, Bonanno C, Grazia Bongiorni M, Bottoni N, Brambilla R, et al. Predictors of Zero X-Ray Ablation for Supraventricular Tachycardias in a Nationwide Multicenter Experience. Circ Arrhythm Electrophysiol 2018; 11: e005592.

10. Zei PC, Quadros KK, Clopton P, Thosani A, Ferguson J, Brodt C, et al. Safety and Efficacy of Minimalversus Zero-fluoroscopy Radiofrequency Catheter Ablation for Atrial Fibrillation: A Multicenter, Prospective Study. J Innov Card Rhythm Manag 2020; 11: 4281-4291.

11. Razminia M, Willoughby MC, Demo H, Keshmiri H, Wang T, D'Silva OJ, et al. Fluoroless Catheter Ablation of Cardiac Arrhythmias: A 5-Year Experience. Pacing Clin Electrophysiol 2017; 40: 425-433.

12. Chiang LLW, Li C, Hong KL, Hui WS, Beh SY, Gong M, et al. The use of minimal fluoroscopy for cardiac electrophysiology procedures: A meta-analysis and review of the literature. Clin Cardiol 2021; 44: 814-823.

13. Newby KH, Zimerman L, Wharton JM, Kent V, Kearney M, Brandon MJ, et al. Radiofrequency ablation of atrial flutter and atrial tachycardias in patients with permanent indwelling catheters. Pacing Clin Electrophysiol 1996; 19: 1612-1617.

14. Regitz-Zagrosek V, Roos-Hesselink JW, Bauersachs J, Blomstrom-Lundqvist C, Cifkova R, De Bonis M, et al. 2018 ESC Guidelines for the management of cardiovascular diseases during pregnancy: The Task Force for the Management of Cardiovascular Diseases during Pregnancy of the European Society of Cardiology (ESC). Eur Heart J 2018; 39: 3165-3241.

15. Marrouche NF, Brachmann J, Andresen D, Siebels J, Boersma L, Jordaens L, et al. Catheter Ablation for Atrial Fibrillation with Heart Failure. N Engl J Med 2018; 378: 417-427.

16. Žižek D, Antolič B, Prolič Kalinšek T, Štublar J, Kajdič N, Jelenc M, at al. Intracardiac echocardiography-guided transseptal puncture for fluoroless catheter ablation of left-sided tachycardias. J Interv Card Electrophysiol 2020: doi: 10.1007/s10840-020-00858-z. Online ahead of print.

17. Baykaner T, Quadros KK, Thosani A, Yasmeh B, Mitra R, Liu E, et al. Safety and efficacy of zero fluoroscopy transseptal puncture with different approaches. Pacing Clin Electrophysiol 2020; 43: 12-18.

18. Verma A, Jiang CY, Betts TR, Chen J, Deisenhofer I, Mantovan R, et al. Approaches to catheter ablation for persistent atrial fibrillation. N Engl J Med 2015; 372: 1812-1822.

19. Calkins H, Hindricks G, Cappato R, Kim YH, Saad EB, Aguinaga L, et al. 2017 HRS/EHRA/ECAS/APHRS/SOLAECE expert consensus statement on catheter and surgical ablation of atrial fibrillation. Europace 2018;20:e1-e160.

20. Christoph M, Wunderlich C, Moebius S, Forkmann M, Sitzy J, Salmas J, et al. Fluoroscopy integrated 3D mapping significantly reduces radiation exposure during ablation for a wide spectrum of cardiac arrhythmias. Europace 2015; 17: 928-937.

\section{Table 1. Background characteristics of the patients}

\begin{tabular}{lllll}
\hline & Overall & $\begin{array}{l}\text { Zero-fluoro } \\
\text { group }\end{array}$ & $\begin{array}{l}\text { Conventional- } \\
\text { fluoro } \\
\text { group }\end{array}$ & p-values \\
\hline $\begin{array}{l}\text { Number of } \\
\text { participants, } \mathbf{n}\end{array}$ & 68 & 16 & 52 & \\
\hline
\end{tabular}




\begin{tabular}{|c|c|c|c|c|}
\hline & Overall & $\begin{array}{l}\text { Zero-fluoro } \\
\text { group }\end{array}$ & $\begin{array}{l}\text { Conventional- } \\
\text { fluoro } \\
\text { group }\end{array}$ & p-values \\
\hline Age, years & $73(68-77)$ & $74(69-78)$ & $73(67-76)$ & 0.43 \\
\hline Male sex, n (\%) & $45(66.2)$ & $8(50.0)$ & $37(71.2)$ & 0.14 \\
\hline Height, cm & $165(156-171)$ & $158(153-167)$ & $166(158-172)$ & 0.08 \\
\hline Weight, kg & $63(56-72)$ & $61(53-67)$ & $63(56-73)$ & 0.35 \\
\hline $\begin{array}{l}\text { Body mass } \\
\text { index, } \mathrm{kg} / \mathrm{m} 2\end{array}$ & $23.3(21.6-26.1)$ & $23.3(21.9-27.9)$ & $23.3(21.6-25.7)$ & 0.76 \\
\hline $\begin{array}{l}\text { Duration of } \\
\text { arrhythmia, } \\
\text { months }\end{array}$ & $28(8-68)$ & $51(26-102)$ & $17(7-66)$ & 0.06 \\
\hline $\begin{array}{l}\text { Previous AF } \\
\text { ablation, n (\%) } \\
\text { Comorbid } \\
\text { conditions, } \mathbf{n} \\
(\%)\end{array}$ & $19(27.9)$ & $7(43.8)$ & $12(23.1)$ & 0.12 \\
\hline Hypertension & $30(44.1)$ & $9(56.2)$ & $21(40.4)$ & 0.39 \\
\hline $\begin{array}{l}\text { Diabetes } \\
\text { mellitus }\end{array}$ & $17(25.0)$ & $4(25.0)$ & $13(25.0)$ & 1.00 \\
\hline $\begin{array}{l}\text { Congestive } \\
\text { heart failure }\end{array}$ & $21(30.9)$ & $6(37.5)$ & $15(28.8)$ & 0.55 \\
\hline $\begin{array}{l}\text { Ischemic heart } \\
\text { disease }\end{array}$ & $16(23.5)$ & $5(31.2)$ & $11(21.2)$ & 0.50 \\
\hline Ischemic stroke & $8(11.8)$ & $4(25.0)$ & $4(7.7)$ & 0.08 \\
\hline $\begin{array}{l}\text { CHA2DS2- } \\
\text { VASc } \\
\text { score } \\
\text { Medications, } n \\
(\%)\end{array}$ & $3.0(2.0-4.0)$ & $4.0(3.0-4.3)$ & $3.0(2.0-4.0)$ & 0.03 \\
\hline $\begin{array}{l}\text { Class I } \\
\text { antiarrhythmic } \\
\text { drugs }\end{array}$ & $12(17.6)$ & $3(18.8)$ & $9(17.3)$ & 1.00 \\
\hline Beta-blockers & $58(85.3)$ & $12(75.0)$ & $46(88.5)$ & 0.23 \\
\hline $\begin{array}{l}\text { Calcium } \\
\text { channel } \\
\text { blockers }\end{array}$ & $10(14.7)$ & $2(12.5)$ & $8(15.4)$ & 1.00 \\
\hline $\begin{array}{l}\text { Amiodarone } \\
\text { use }>3 \text { months } \\
\text { before ablation } \\
\text { Examination } \\
\text { results }\end{array}$ & $17(25.0)$ & $3(18.8)$ & $14(26.9)$ & 0.74 \\
\hline $\begin{array}{l}\text { LV ejection } \\
\text { fraction, \% }\end{array}$ & $58(39-63)$ & $58(51-63)$ & $55(36-63)$ & 0.32 \\
\hline $\begin{array}{l}\text { LA diameter, } \\
\text { mm }\end{array}$ & $44(40-49)$ & $45(39-48)$ & $44(40-49)$ & 0.90 \\
\hline $\begin{array}{l}\text { B-type } \\
\text { natriuretic } \\
\text { peptide, pg/mL }\end{array}$ & $139(67-382)$ & $135(90-226)$ & $140(60-415)$ & 0.94 \\
\hline
\end{tabular}




\begin{tabular}{|c|c|c|c|c|}
\hline & Overall & $\begin{array}{l}\text { Zero-fluoro } \\
\text { group }\end{array}$ & $\begin{array}{l}\text { Conventional- } \\
\text { fluoro } \\
\text { group }\end{array}$ & p-values \\
\hline \multicolumn{5}{|l|}{$\begin{array}{l}\text { Catheter } \\
\text { ablation for, } \mathrm{n} \\
(\%)\end{array}$} \\
\hline Paroxysmal AF & $35(51.5)$ & $3(18.8)$ & $32(61.5)$ & 0.004 \\
\hline Persistent AF & $15(22.1)$ & $7(43.8)$ & $8(15.4)$ & 0.03 \\
\hline $\begin{array}{l}\text { Atrial } \\
\text { tachycardia }\end{array}$ & $18(26.5)$ & $8(50.0)$ & $10(19.2)$ & 0.02 \\
\hline $\begin{array}{l}\text { Typical atrial } \\
\text { flutter } \\
\text { Cardiac } \\
\text { electronic } \\
\text { implantable } \\
\text { device, n (\%) }\end{array}$ & $4(5.9)$ & $0(0.0)$ & $4(7.7)$ & 0.57 \\
\hline Pacemaker & $36(52.9)$ & $13(81.2)$ & $23(44.2)$ & 0.01 \\
\hline ICD & $20(29.4)$ & $2(12.5)$ & $18(34.6)$ & 0.12 \\
\hline CRT-D & $12(17.6)$ & $1(6.2)$ & $11(21.2)$ & 0.27 \\
\hline $\begin{array}{l}\text { Reason for } \\
\text { device } \\
\text { implantation, } \mathbf{n} \\
(\%)\end{array}$ & & & & \\
\hline $\begin{array}{l}\text { Sick sinus } \\
\text { syndrome }\end{array}$ & $26(38.2)$ & $7(43.8)$ & $19(36.5)$ & 0.77 \\
\hline $\begin{array}{l}\text { Atrioventricular } \\
\text { block or AF } \\
\text { bradycardia }\end{array}$ & $16(23.5)$ & $7(43.8)$ & $9(17.3)$ & 0.04 \\
\hline $\begin{array}{l}\text { Ventricular } \\
\text { arrhythmia } \\
\text { and/or heart } \\
\text { failure }\end{array}$ & $30(44.1)$ & $3(18.8)$ & $27(51.9)$ & 0.02 \\
\hline $\begin{array}{l}\text { Implanted } \\
\text { leads, n (\%) }\end{array}$ & & & & \\
\hline $\begin{array}{l}\text { Atrial leads } \\
\text { Lead location }\end{array}$ & $67(98.5)$ & $16(100)$ & $51(98.1)$ & 1.00 \\
\hline RA appendage & $63(89.6)^{*}$ & $15(93.8)$ & $45(88.2) *$ & 1.00 \\
\hline Septum & $4(6.0)$ & $1(6.2)$ & $3(5.9)$ & \\
\hline $\begin{array}{l}\text { RV leads } \\
\text { Lead location }\end{array}$ & $68(100.0)$ & $16(100.0)$ & $52(100.0)$ & 1.00 \\
\hline His-septum & $7(10.3)$ & $1(6.2)$ & $6(11.5)$ & 1.00 \\
\hline RV apex & $61(89.7)^{*}$ & $15(93.8)$ & $46(88.5)^{*}$ & \\
\hline LV leads & $12(17.6)$ & $1(6.2)$ & $11(21.2)$ & 0.27 \\
\hline $\begin{array}{l}\text { Periods from } \\
\text { last lead } \\
\text { implantation, } \\
\text { months }\end{array}$ & $54.5(14.5-200.5)$ & $55.5(35.3-88.5)$ & $54.5(10.8-203.0)$ & 0.47 \\
\hline
\end{tabular}




\begin{tabular}{lllll}
\hline & Overall & $\begin{array}{l}\text { Zero-fluoro } \\
\text { group }\end{array}$ & $\begin{array}{l}\text { Conventional- } \\
\text { fluoro } \\
\text { group }\end{array}$ & p-values \\
\hline $\begin{array}{l}\text { Device } \\
\text { implantation } \\
\begin{array}{l}\text { within 3 } \\
\text { month, } \mathbf{n}(\%)\end{array}\end{array}$ & $5(7.4)$ & $0(0.0)$ & $5(9.6)$ & 0.33 \\
\hline
\end{tabular}

Data are n (\%) and median (interquartile range).

*The atrial and ventricular leads were inserted via persistent left superior vena cava in one patient.

AF: atrial fibrillation, CS: coronary sinus, CRT-D: cardiac resynchronization therapy defibrillator, LA: left atrial, LV: left ventricular, ICD: implantable cardioverter defibrillator, RA: right atrial, RV: right ventricular

Table 2. Results of each measurement and proportion

\begin{tabular}{|c|c|c|c|}
\hline & Overall & Zero-fluoro group & Conve \\
\hline Number of participants, $n$ & 68 & 16 & 52 \\
\hline \multicolumn{4}{|l|}{ Ablation catheter types, $n(\%)$} \\
\hline Radiofrequency ablation & $61(89.7)$ & $16(100.0)$ & $45(86$. \\
\hline Cryo ablation* & $7(10.3)$ & $0(0.0)$ & $7(13.5)$ \\
\hline \multicolumn{4}{|l|}{ 3-D mapping systems, n (\%) } \\
\hline CARTOB 3 & $49(72.1)$ & $16(100.0)$ & $33(63$. \\
\hline EnSite Precision & $18(26.5)$ & $0(0.0)$ & $18(34$. \\
\hline RHYTHMIA HDx & $1(1.5)$ & $0(0.0)$ & $1(1.9)$ \\
\hline \multicolumn{4}{|l|}{ CS catheter insertions, n (\%) } \\
\hline SVC approach & $56(88.9)$ & $10(66.7)$ & $46(95.8$ \\
\hline IVC approach & $7(11.1)$ & $5(33.3)$ & $2(4.2)$ \\
\hline Trans-septal procedure countable, n (\%) & $57(83.8)$ & $15(93.8)$ & $42(80$. \\
\hline \multicolumn{4}{|l|}{ Ablation procedures, $n(\%)$} \\
\hline PV isolation & $55(80.9)$ & $13(81.2)$ & $42(80.8$ \\
\hline LA linear ablation + & $33(48.5)$ & $14(87.5)$ & $19(36$. \\
\hline $\mathrm{SVC}$ isolation & $6(8.8)$ & $2(12.5)$ & $4(7.7)$ \\
\hline Focal ablation, LA side & $4(5.9)$ & $1(6.2)$ & $3(5.8)$ \\
\hline Focal ablation, RA side & $7(10.3)$ & $4(25.0)$ & $3(5.8)$ \\
\hline Cavotricuspid isthmus ablation & $22(32.4)$ & $7(43.8)$ & $15(28$. \\
\hline \multicolumn{4}{|l|}{ Measurements, } \\
\hline Total procedure time, min & $172(145-232)$ & $215(138-268)$ & $172(15$ \\
\hline Total radiofrequency time, $\min$ & $1552(1189-2261)$ & $1715(1189-2401)$ & $1552(1$ \\
\hline Total ablation points & $95(74-135)$ & $118(85-145)$ & $94(72-$ \\
\hline Time from puncture to achieve trans-septal approach,++ min & $25(20-29)$ & $27(18-34)$ & $24(20-$ \\
\hline Total fluoroscopy time, min & $13(10-18)$ & - & $13(10-$ \\
\hline Total fluoroscopy dose, $\mathrm{mGy} / \mathrm{cm} 2$ & $58.0(29.3-109.7)$ & - & $58.0(2$ \\
\hline Recurrence at 6 month after procedure, $\mathrm{n}(\%)$ & $22 / 58(37.9)$ & $7 / 12(53.8)$ & $15 / 45($ \\
\hline \multicolumn{4}{|l|}{ Atrial high-rate episode, \%/day } \\
\hline Pre-procedure & $10.5(1.1-36.5)$ & $5.8(1.3-100.0)$ & $10.5(1$ \\
\hline Six month after procedure & $0.0(0.0-0.9)$ & $0.1(0.0-2.8)$ & $0.0(0.0$ \\
\hline Absolute reduction at 6 mont & $1.7(0.0-20.0)$ & $3.2(0.3-93.9)$ & $1.0(0.0$ \\
\hline Lead failure requires device exchange, $n(\%)$ & $0(0.0)$ & $0(0.0)$ & $0(0.0)$ \\
\hline
\end{tabular}


Data are n (\%) and median (interquartile range).

* One case required additional radiofrequency application.

+ Linear ablation includes left atrial roof line, bottom line, mitral isthmus,

and anterior lines

++ Only for those who underwent trans-septal procedure immediately after puncture and CS catheter placement.

CS: coronary sinus, IVC: inferior vena cava, LA: left atrial, PV: pulmonary vein, RA: right atrial, SVC: superior vena cava

\section{Figure legends}

A

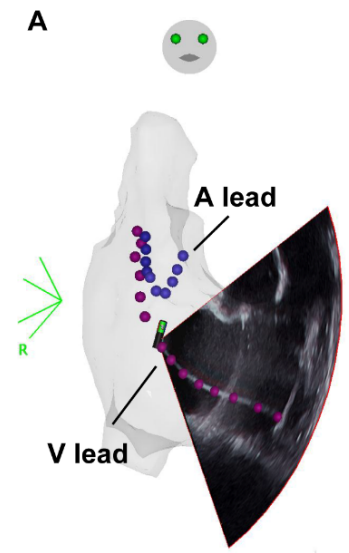

B

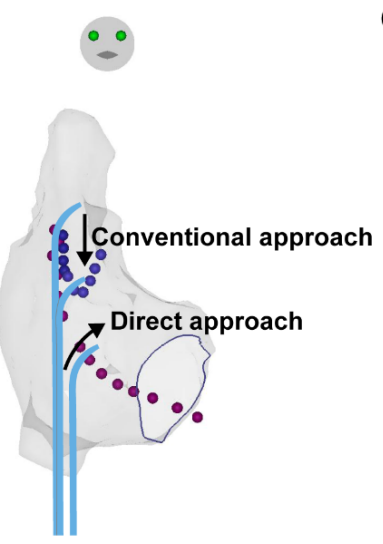

C

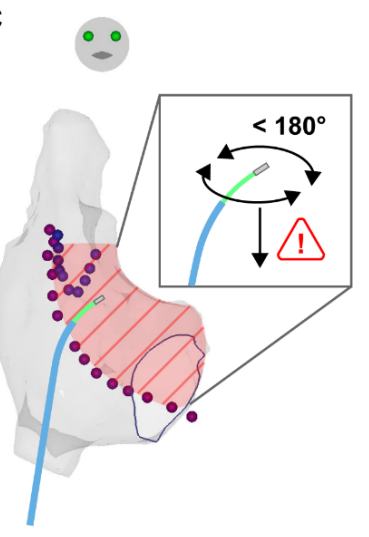

\section{Figure 1. Procedures in the Zero-fluoro ablation.}

1. The atrial (A) lead (blue dots) and ventricular (V) lead (pink dots) positions in the right atrium was

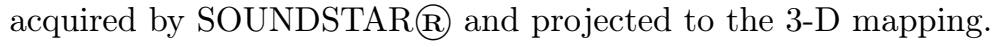

2. To achieve trans-septal access, we directly positioned the tip of the long sheath next to the atrial septum in the zero-fluoro group (Direct approach) instead of dragging it down from the superior vena cava (Conventional approach).

3. Catheter manipulation was limited to a $180^{\circ}$ turn above the deflection of the leads (red shaded area) not to trap and dislodge the leads. Interaction with the catheter and leads was checked using intracardiac echocardiography not to entangled the leads, especially when pulling it downward. 